\title{
A NEW PRESENTATION OF COMBINATION SYNDROME
}

F. Ahmad, N. Yunus, F. McCord. A New Presentation of Combination Syndrome. Annal Dent Univ Malaya 2008; 15(2): 94-99.

\begin{abstract}
This article reviews the concept of Combination Syndrome and presents a clinical case of a patient with a modern variation to this clinical scenario. The clinical procedures involved in the provision of a maxillary complete denture against a mandibular implant-supported complete fixed prosthesis is described with some suggestions on how to optimise the treatment outcome for the patient.
\end{abstract}

Key words: dental implants, prostheses, $21^{\text {st }}$ Century Combination Syndrome; lingualised occlusion

\section{Introduction}

Combination Syndrome was originally termed by Kelly (1) in 1972 to describe the clinical scenario of a complete maxillary denture opposed by six or eight anterior mandibular teeth (Figure 1). In addition, a mandibular removable partial denture was typically present, to restore the missing posterior mandibular teeth (Figure 2)

Kelly stated that patients in this category presented with 4 salient clinical findings:

- Fibrous (flabby) anterior maxillary ridges. He considered that the effect of occlusal forces by the mandibular teeth on the maxillary denture anteriorly caused resorption of bone which was replaced by fibrous tissue.

- Relatively enlarged tuberosities which he considered to have "grown".

- Increased resorption of the residual mandibular ridge.

- Inflammation of the hard palate, often with papillary hyperplasia present.

Whether these explanations are necessarily accurate or not is almost of no consequence, as the clinician is, ultimately, faced with clinical difficulties which are of sufficient difficulty to present problems if an acceptable return to and of function are to be achieved.

In essence, the first three of these problem areas are essentially of a clinical complexity as to require treatment by a dental practitioner with some experience in Removable Prosthodontist, not necessarily a specialist in Prosthodontics.
Case Report

F. Ahmad ${ }^{1}$, N. Yunus ${ }^{1}$, F. McCord ${ }^{2}$

${ }^{1}$ Department of Prosthetic Dentistry

Faculty of Dentistry, University of Malaya

50603 Kuala Lumpur, Malaysia

Tel: $603-79674881$

Fax: 603-79674535

Email: horsiah@um.edu.my

${ }^{2}$ Department of Restorative Dentistry

Glasgow Dental Hospital and School

378, Sauchiehall Street

Glasgow, G2 3JZ

Correspondence author: Norsiah Yunus

Treatment of papillary hyperplasia should be treatable by a general dental practitioner using a combination of tissue conditioner and oral hygiene measures, perhaps with appropriate antifungal therapy in common with other types of dentureinduced papillary inflammation.

The practising dentist is therefore faced with three areas of difficulty which relate to:

I. Recording the definitive impression of the maxillary arch.

II. Restoration of the mandibular arch.

III. Recording appropriate intermaxillary relations

1. Recording the definitive impression of the maxillary arch.

When a markedly displaceable tissue is present in the anterior maxillary ridge, then the problem is essentially one of support; the displaceable anterior (fibrous or flabby) ridge being more susceptible to displacement / distortion during function. For this reason, a minimally displacive impression (i.e. using minimum pressure) technique is recommended as follows (2):

o After recording the primary impression, make a $2 \mathrm{~mm}$ spaced, non-perforated custom tray.

o After securing a peripheral seal with tracing compound, record the impression in medium- bodied polyvinyl siloxane (PVS) impression material.

- Remove the area of the tray, including the PVS impression (Figure 3), re-insert the tray and inject light-bodied PVS into the area corresponding to the fibrous ridge. The final 


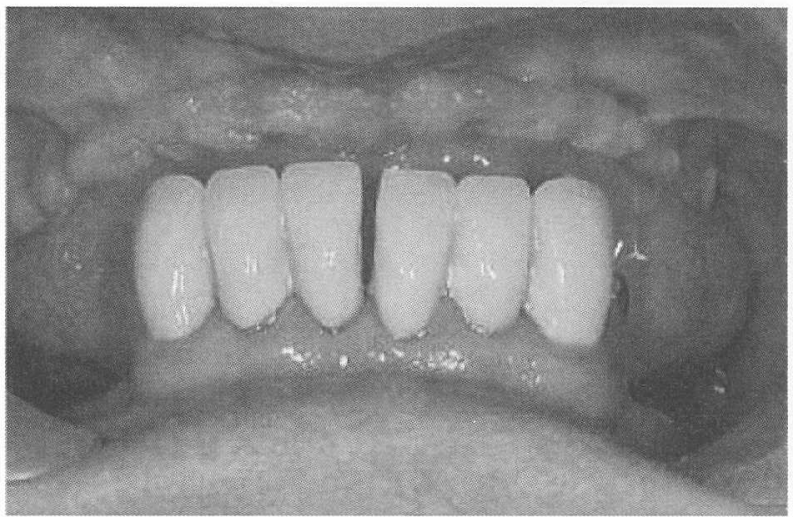

Figure 1: Edentulous maxilla and partially dentate mandible of a patient without the prostheses in position.

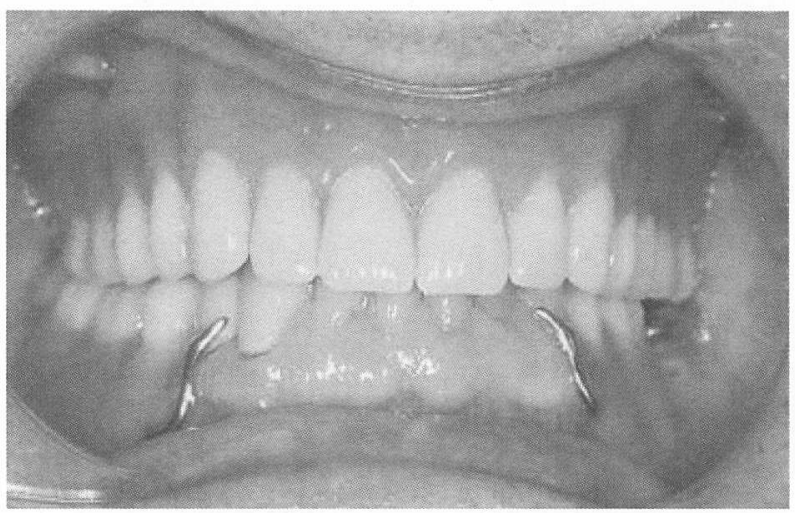

Figure 2: Maxillary complete denture with mandibular Kennedy class I removable partial denture.

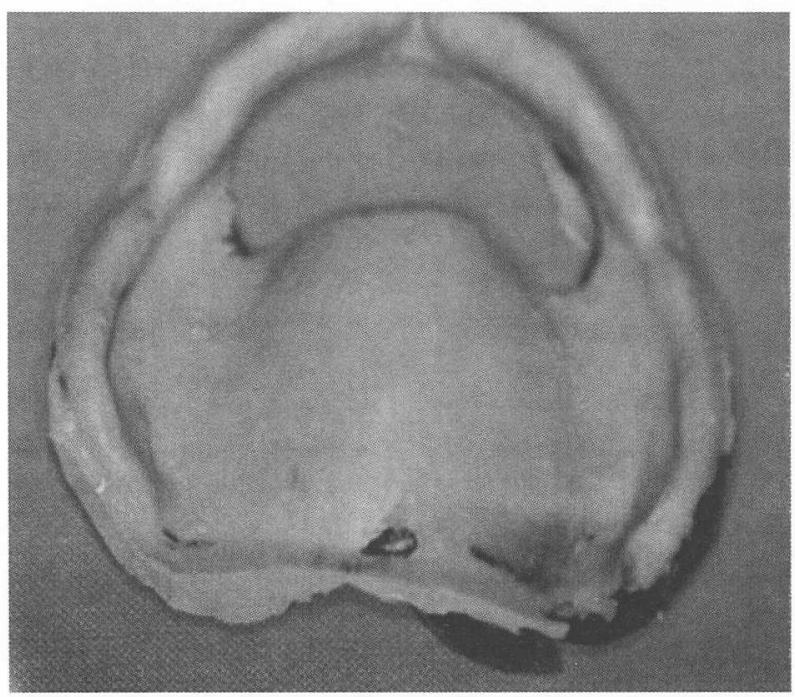

Figure 3: Maxillary impression after modification showing the window made at around the region of flabby area.

impression should record the flabby ridge with minimal displacement (Figure 4).

o After placing the definitive impression in the appropriate disinfectant solution, pour the master cast.
II. Restoring the mandibular arch.

The restoration of missing posterior mandibular teeth with a Kennedy class 1 type of removable partial denture was widely adopted as a favoured treatment option. In recent times, the need to restore missing molar teeth, in appropriate cases, has been questioned by colleagues from Nijmegen (3) and hence the shortened dental arch philosophy evolved whereby it was shown that acceptable oral (masticatory) function may be maintained in reduced dentitions; this philosophy is now practised universally. Shortened dental arch principles may also be used to avoid the biomechanical problems inherent in the provision of Kennedy class 1 removable partial denture. The use of resin-bonded or conventional cantilevered (Figure 5) bridges to extend short arches opposing complete dentures has been recommended (2) as an alternative to a conventional Kennedy 1 partial denture.

Whichever course of treatment is used, it should be done at the same time as the replacement maxillary complete denture.

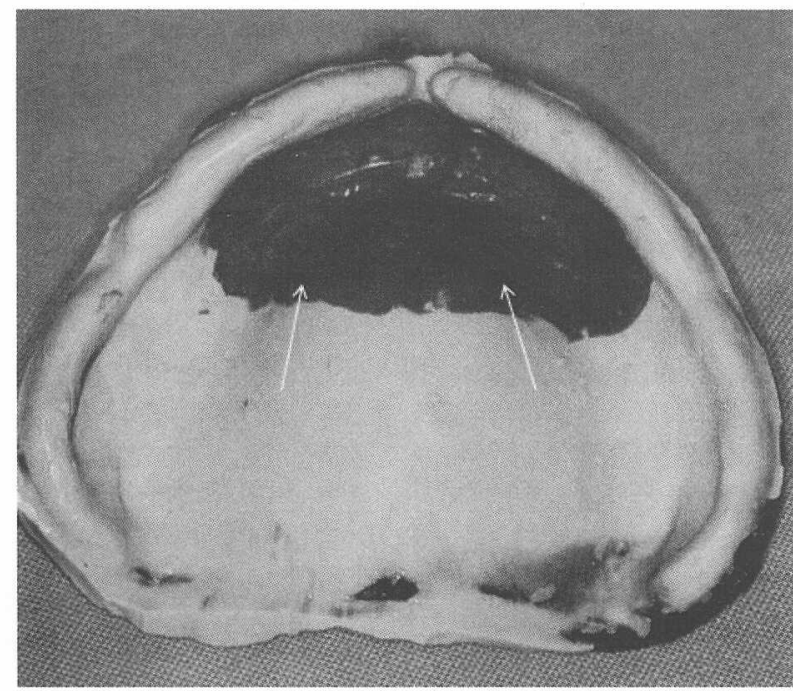

Figure 4: Definitive impression with the light-body PVS (arrows) recording the anterior flabby ridge.

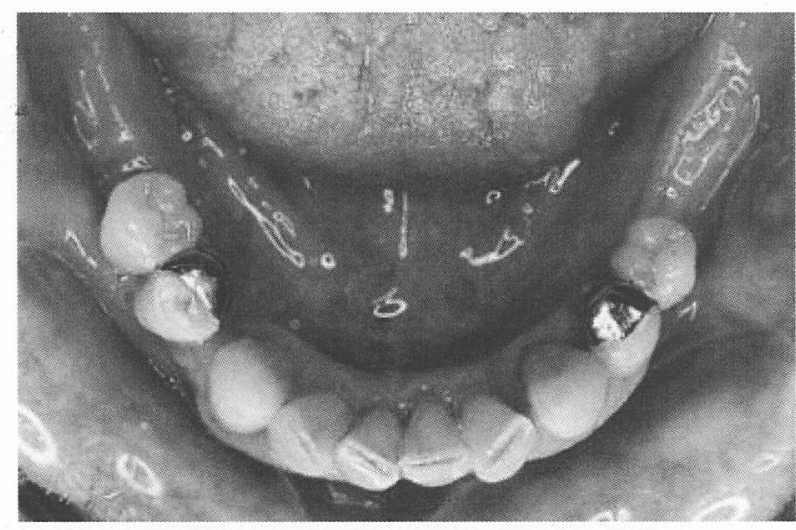

Figure 5: Shortened dental arch showing cantilever fixed prosthesis to replace mandibular second premolar on each side. 
III. Recording appropriate intermaxillary relations.

If the patient has only vertical mandibular movements, then a conventional registration technique may be used using upper and lower rims. If, however, the patient has ruminatory (i.e. lateral and protrusive excursive) movements, then it is recommended that an intra-oral (gothic arch or arrowhead) tracing (2) be recorded in addition to a facebow transfer to better relate the maxillary denture to the mandibular axis and to mandibular movement in the interests of stability of the maxillary denture. If necessary, the maxillary denture teeth may be restored with composite, amalgam or gold (Figure 6) by having the patient create functionally-generated occlusal surfaces.

The above is a review of Kelly's form of Combination Syndrome with an outline of possible ways to treat patients with this clinical condition. Currently, a new form of $21^{\text {st }}$ century Combination Syndrome is evolving and this case report highlights how it may be treated in an attempt to overcome future problems similar to those described by Kelly (1).

\section{CASE REPORT}

A 63 years old man came to the Department of Prosthetic Dentistry, Faculty of Dentistry, University of Malaya in July 2007 complaining of slight looseness of his mandibular implantsupported fixed prosthesis. Five implants had been placed in the mandible 10 years previously and the current prosthesis was 2 years old. Intraoral examination revealed the maxillary edentulous arch was large, ovoid in form and the palate was of moderate depth. The anterior maxillary ridge was flabby and, from the dental panaromic radiograph, there was evidence of bilateral pneumatisation of the maxillary sinuses. In the mandibular arch, the fixed prosthesis was supported by 5 intra-foraminal implants; the prosthesis was loose as some of the abutment screws had loosened.

After consultation, the patient agreed to have a replacement maxillary complete denture and a replacement mandibular implant-supported fixed prosthesis.

Primary impressions for the maxillary and mandibular arches were made in alginate impression material (Aroma Fine, GC, Tokyo, Japan). A 2mm spaced, non-perforated custom tray for the maxillary arch was constructed. Prior to recording the definitive impression, peripheral seal was achieved via greenstick tracing compound and an initial impression taken using a medium-body PVS impression material (Reprosil, Dentsply, Milford, USA). Using the technique described by McCord et al. (2), a window was cut in the tray in the region of the flabby ridge (Figure 3), the tray re-inserted and light-bodied PVS (Reprosil, Dentsply, Milford, USA) injected over the flabby tissues of the anterior maxillary ridge, care being taken to reduce unnecessary hydraulic pressure (4) (Figure 4).

The definitive impression for the mandibular arch was made using polyether impression material (Impregum, 3M ESPE, Seefeld, Germany) in an open window custom tray that accomodated the impression copings. Laboratory analogues were attached to the impression copings and gingival mask material was syringed around the analogues; and the cast was poured in vacuum-mixed diestone (Figure 7).

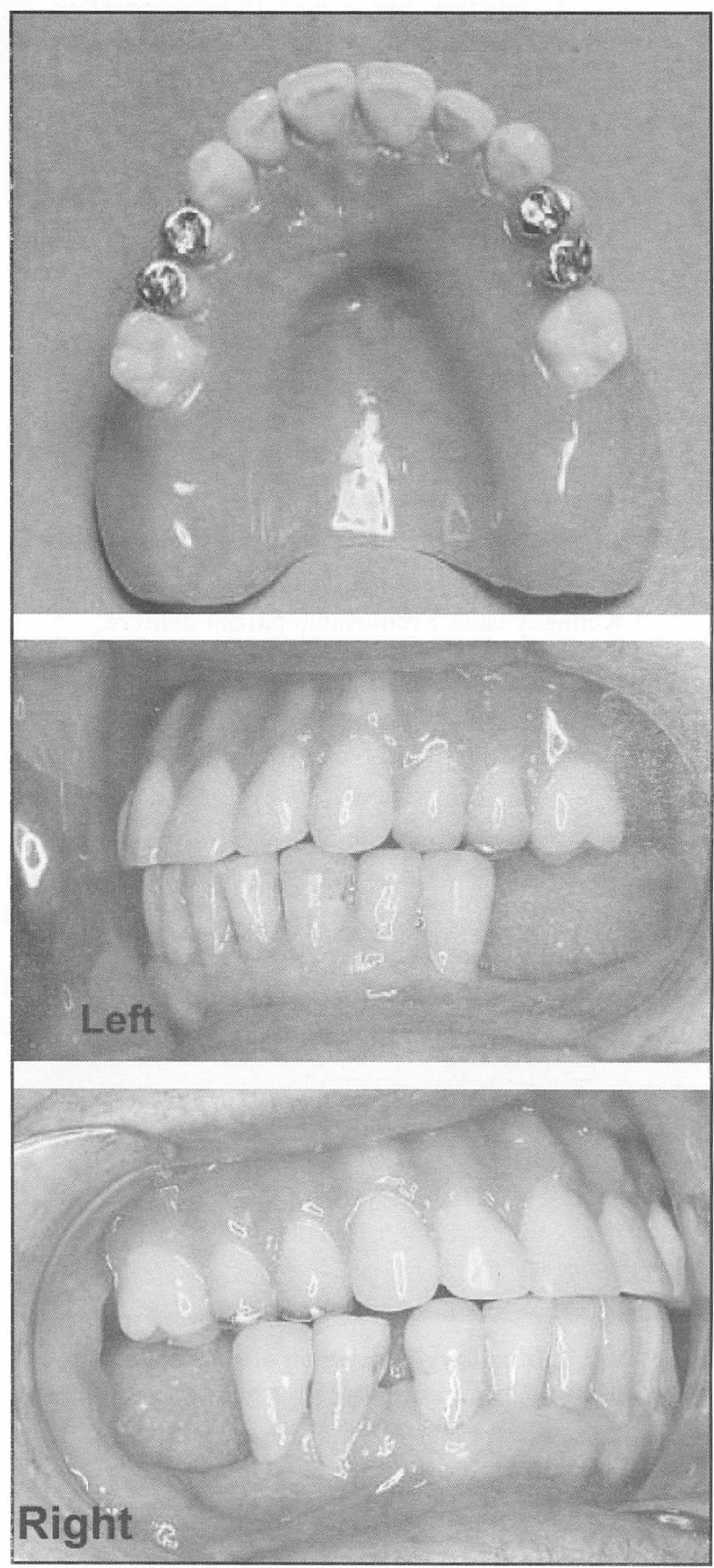

Figure 6: (a) Restoration of maxillary complete denture with gold overlays (b) Intraoral lateral view showing occlusal relationship with mandibular natural teeth (Left and right views). 


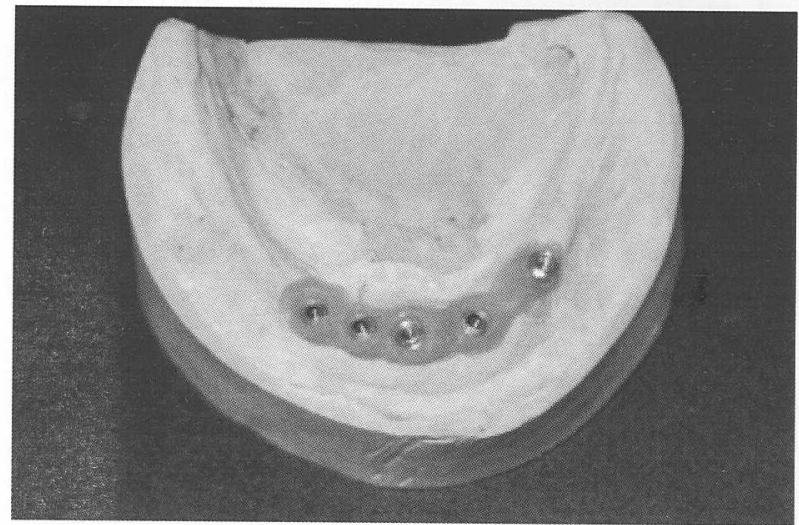

Figure 7: Mandibular working stone cast with soft tissue produced from gingival mask around the implant analogues.

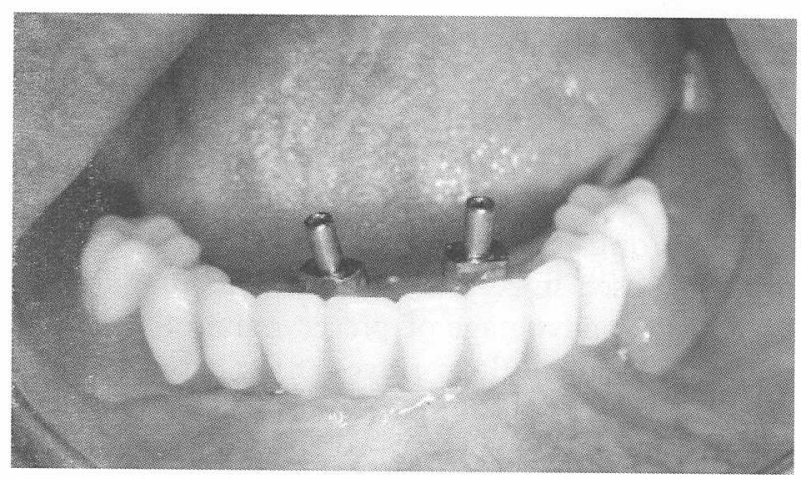

Figure 8: Two impression copings and posts were used to stabilize the mandibular wax denture during teeth try-in (the posts were shorten before the occlusion was checked).

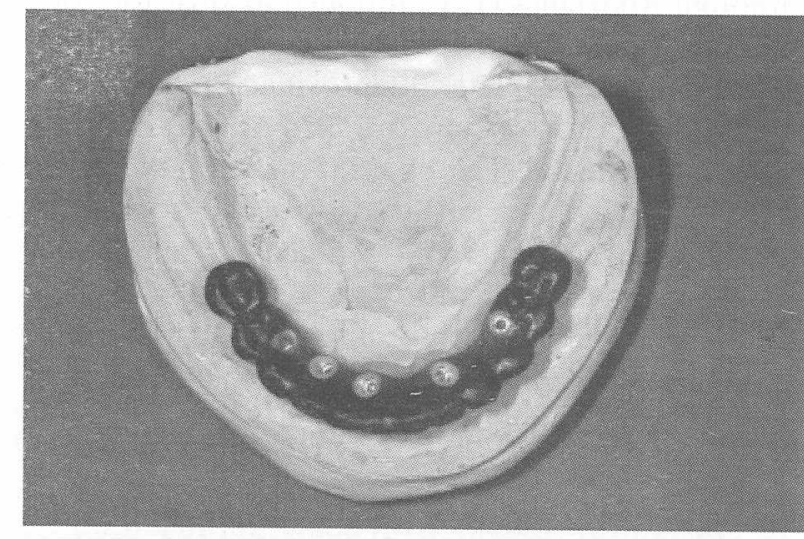

Figure 9: Occlusal view of full contour wax-up showing access holes for screw-retained mandibular prosthesis.

The intermaxillary relations were recorded using the conventional method as in complete denture construction except that, for this case, the mandibular record base was stabilized by incorporating two impression posts into the record base. Stabilisation of the record base afforded easier recording of the jaw relationship and this is particularly helpiul in cases where the mandibuiar ridge is severely resorbed. Facebow registration and centric relation record were made.
The casts were mounted on a semiadjustable articulator and the denture teeth were set-up with lingualized occlusion as this has been shown to be the preferred occlusal form where stability of one or both prostheses is compromised (5). The wax dentures were tried-in with the mandibular base secured by the two impression copings and posts (Figure 8) and both prostheses assessed for occlusion, appearance and phonetics.

The resin framework for the mandibular prosthesis was fabricated using an autopolymerising resin (GC Pattern Resin, Tokyo, Japan) on plastic UCLA type abutments (Renew Biocare Corp., Cal, USA). A full contour waxing on the resin framework was completed (Figure 9) using the index of the mandibular trial wax-up. The wax was cut back and the assembly was cast in semi-precious alloy. The framework was evaluated for fit in the mouth and as a rocking movement was detected, the framework was sectioned and replaced on the implants. The gap was filled with autopolymerising resin (GC Pattern Resin, Tokyo, Japan - Figure 10) and the framework was soldered and retried in the mouth. Once the accuracy of fit was satisfactory, the centric relation record was verified using reinforced wax (Aluwax, Mich., USA).

The casts were remounted on the articulator and porcelain was applied to the framework (Figure 11). A cobalt-chromium palatal baseplate was fabricated for the maxillary complete denture (Figure 12). The teeth set-up of the complete denture was again checked and adjusted for lingualized occlusion before processing (Figure 13).

At insertion stage, the mandibular implantsupported bridge were screwed in and the occlusion with the maxillary complete denture was adjusted. Articulating paper was used for occlusal adjustment in centric and lateral excursions. The patient was instructed on oral and denture hygiene. The patient was reviewed at one week post-insertion (Figure 13). The importance of regular review visits was emphasized to the patient because of the complicated design of mandibular prosthesis and the potential for Combination syndrome as, although

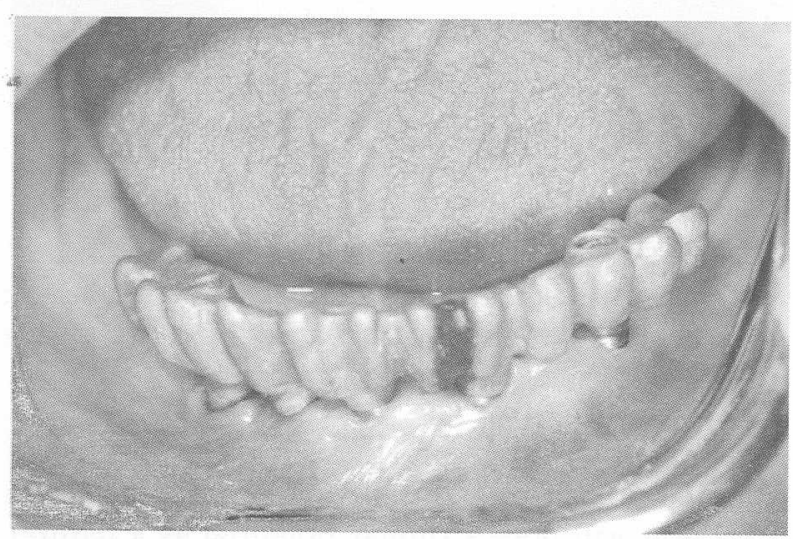

Figure 10: Sectioned framework which was replaced on the implants and joined intraorally with pattern resin. 


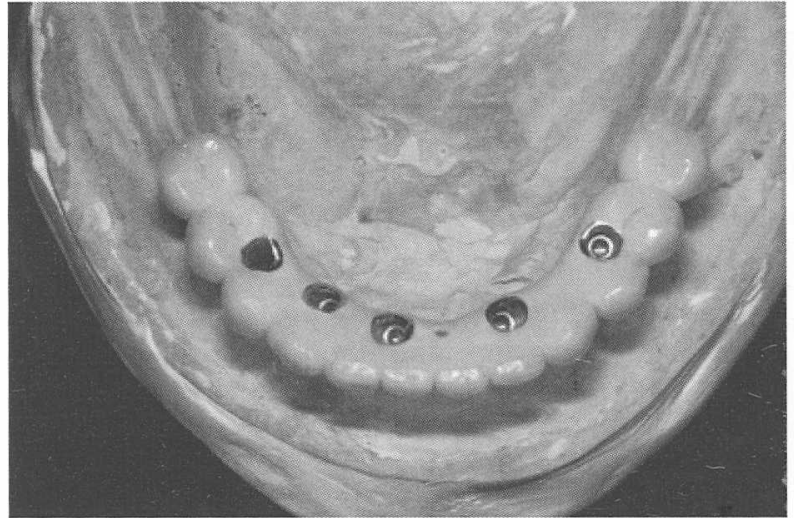

Figure 11: Completed mandibular implant-supported fixed prosthesis.

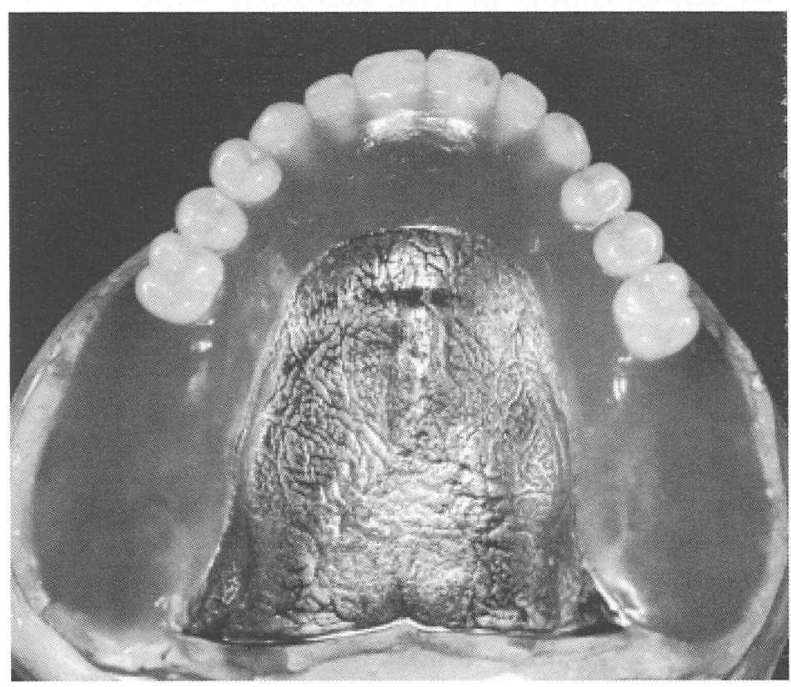

Figure 12: Cobalt-chromium plate for maxillary complete denture.

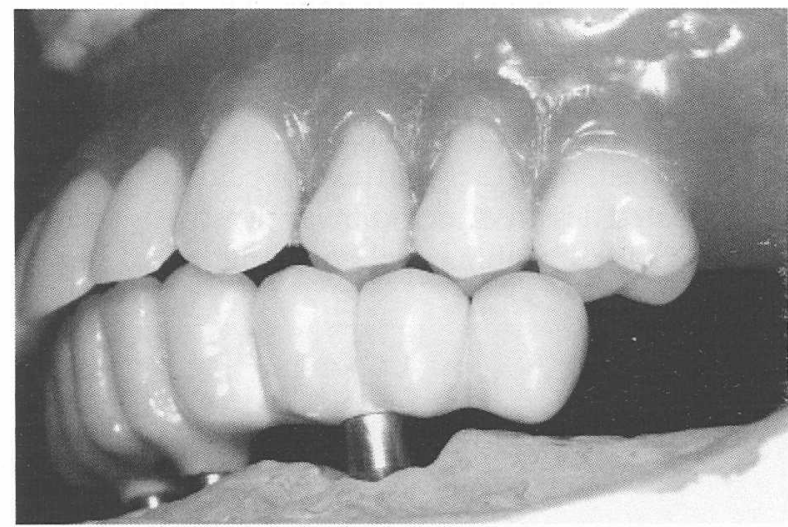

Figure 13: Maxillary wax-up denture and mandibular implant fixed-prosthesis in lingualized occlusion.

the implant-stabilised prosthesis is preferable to the removable option, the presence of the fixed prosthesis will pose a similar potential as a natural dentition on the edentulous maxillary ridge.

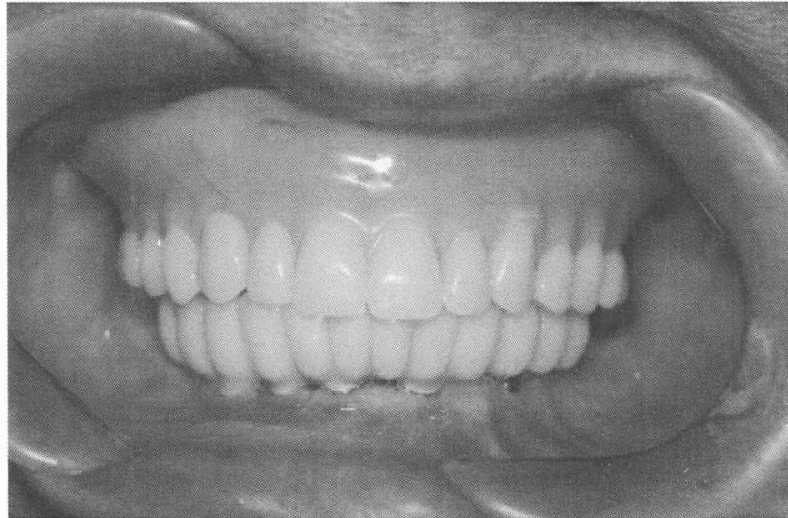

Figure 14: Final prostheses at 1 week recall appointment.

\section{DISCUSSION}

Mandibular fixed-prostheses supported by implants in interforaminal region and opposing maxillary complete denture have been shown to have good clinical long-term results $(6,7)$. This treatment modality used in restoring edentulous mandibular arch has the advantage of preservation of posterior mandibular edentulous ridges (8). There has been considerable debate on the pros and cons of the design of cantilevers (9-12) because the location of inferior dental canal may restrict implant placement beyond mental foramen especially in severely resorbed ridges.

According to the literature, it is possible to achieve posterior occlusion by cantilever extension although Rodrigues (13) cautioned against too long an extension. In the present case, the distal cantilever of two premolars bilaterally provided an acceptable shortened dental arch and provided adequate posterior occlusion. This concept may also be looked at as a problem-orientated strategy to reduce complex surgical intervention in posterior mandible.

Locking of the occlusion was avoided in the case by the use of lingualized occlusion. This is because in this occlusal concept, the maxillary buccal cusps are reduced in height and the principal occlusal contacts are between the maxillary palatal (lingual) cusps and the central fossae / marginal ridges of the mandibular posterior teeth in retruded contact position $(14,15)$. As in bilateral balanced articulation, simultaneous contact does exist on the working and non-working side during lateral movement and in the anterior and posterior teeth during protrusive movement. This occlusal arrangement is necessary for the maxillary complete denture to remain stable during function.

The rate of bone resorption beneath maxillary complete denture opposed by implant-supported prosthesis was reported to be similar to those described by Kelly with natural dentition (16). Therefore as a precaution against further 
deterioration in the anterior maxillary ridge, no anterior tooth contact in maximum occlusion was planned for this patient. This follows the recommendation made by Lang and Razzoog (5) when providing patients with mandibular implantsupported fixed prosthesis.

\section{CONCLUSION}

The concept of Combination Syndrome is reviewed and the implications that current techniques may lead to a re-emergence of this condition are considered. In consequence, some clinical procedures are highlighted, such as the impression technique, prosthesis design and occlusal scheme appropriate in the rehabilitation of this type of patient.

\section{REFERENCES}

1. Kelly E. Changes caused by a mandibular removable partial denture opposing a maxillary complete denture. J Prosthet Dent. 1972; 27 : 140-50.

2. McCord JF, Smith P, Grey, N. Treatment of Edentulous Patients; Churchill Livingstone 2004.

3. Witter DJ, van Elteren P, Käyser AF. Migration of teeth in shortened dental arches. J Oral Rehabil. 1987; 14: 321-9.

4. Al-Ahmad A, Masri R, Driscoll CF, von Fraunhofer J, Romberg E. Pressure generated on a simulated mandibular oral analog by impression materials in custom trays of different design. J Prosthodont. 2006; 15: 95-101.

5. Lang BR and Razzoog ME. Lingualised Occlusion: Tooth molds and an Occlusal scheme for edentulous implant patients. Implant Dent. 1992; 1: 204-211.

6. Lindquist LW, Carlsson GE, Jemt T. A prospective 15-year follow-up study of mandibular fixed prostheses supported by osseointegrated implants. Clinical results and marginal bone loss. Clin Oral Implants Res. 1996; 7: 329-36.
7. Wennerberg A, Carlsson GE, Jemt T. Influence of occlusal factors on treatment outcome: a study of 109 consecutive patients with mandibular implant-supported fixed prostheses opposing maxillary complete dentures. Int $\mathrm{J}$ Prosthodont. 2001; 14: 550-5.

8. Sennerby L, Carlsson GE, Bergman B, Warfvinge J. Mandibular bone resorption in patients treated with tissue-integrated prostheses and in complete-denture wearers. Acta Odontol Scand. 1988; 46: 135-40.

9. Adell R, Lekholm U, Rockler B, Brånemark PI. A 15-year study of osseointegrated implants in the treatment of the edentulous jaw. Int $\mathbf{J}$ Oral Surg. 1981; 10: 387-416.

10. Brånemark PI, Hansson BO, Adell R, Breine U, Lindström J, Hallén $\mathrm{O}$, Ohman A. Osseointegrated implants in the treatment of the edentulous jaw. Experience from a 10-year period. Scand J Plast Reconstr Surg Suppl. 1977; 16: 1-132.

11. T Albrektsson, A multicenter report of osseointegrated oral implants. J Prosthet Dent; 1988: 60. 75-84.

12. Brosky ME, Korioth TW, Hodges JJ. The anterior cantilever in the implant-supported screw-retained mandibular prosthesis. J Prosthet Dent. 2003; 89: 244-9.

13. Rodriguez AM, Aquilino SA, Lund PS. Cantilever and implant biomechanics: a review of the literature, J Prosthodont 1994; 3: 114-8.

14. Lang BR. Complete denture occlusion. Dent Clin North Am. 2004; 48: 641-65.

15. Garcia LT, Bohnenkamp DM. Lingualized occlusion: an occlusal solution for edentulous patients. Pract Proced Aesthet Dent. 2005; 17 : 5.

16. Barber HD, Scott RF, Maxson BB, Fonseca RJ. Evaluation of anterior maxillary alveolar ridge resorption when opposed by the transmandibular implant. J Oral Maxillofac Surg. 1990; 48: 1283-7. 